\section{Pacific Northwest}

National Laboratory

Operated by Battelle for the

U.S. Department of Energy

\title{
RDCDS Meteorological Component Quick Installation Guide
}

LK Berg

MS Pekour

October 2007

Prepared for the U.S. Department of Energy

under Contract DE-AC05-76RL01830 


\title{
DISCLAIMER
}

This report was prepared as an account of work sponsored by an agency of the United States Government. Neither the United States Government nor any agency thereof, nor Battelle Memorial Institute, nor any of their employees, makes any warranty, express or implied, or assumes any legal liability or responsibility for the accuracy, completeness, or usefulness of any information, apparatus, product, or process disclosed, or represents that its use would not infringe privately owned rights. Reference herein to any specific commercial product, process, or service by trade name, trademark, manufacturer, or otherwise does not necessarily constitute or imply its endorsement, recommendation, or favoring by the United States Government or any agency thereof, or Battelle Memorial Institute. The views and opinions of authors expressed herein do not necessarily state or reflect those of the United States Government or any agency thereof.

\author{
PACIFIC NORTHWEST NATIONAL LABORATORY \\ operated by \\ BATTELLE \\ for the \\ UNITED STATES DEPARTMENT OF ENERGY \\ under Contract DE-AC05-76RL01830
}

Printed in the United States of America
Available to DOE and DOE contractors from the Office of Scientific and Technical Information,
P.O. Box 62, Oak Ridge, TN 37831-0062;
ph: (865) 576-8401
fax: $(865)$ 576-5728
email: reports@adonis.osti.gov

\begin{abstract}
Available to the public from the National Technical Information Service, U.S. Department of Commerce, 5285 Port Royal Rd., Springfield, VA 22161 ph: (800) 553-6847 fax: $(703) 605-6900$ email: orders@ntis.fedworld.gov online ordering: http://www.ntis.gov/ordering.htm
\end{abstract}

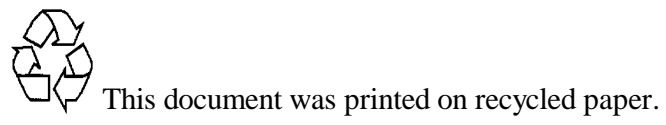


PNNL-17107

\title{
RDCDS Meteorological Component Quick Installation Guide
}

\author{
L. K. Berg \\ M. S. Pekour
}

October 2007

Prepared for the U.S. Department of Homeland Security under a Related Services Agreement with the U.S. Department of Energy under Contract DE-AC05-76RL01830

Pacific Northwest National Laboratory Richland, Washington 99352 



\section{Summary}

This guide provides step-by-step instructions for the deployment of one of the Rapidly Deployable Chemical Defense System (RDCDS) weather stations and central control system. Instructions for the deployment and operation of the Atmospheric Systems Corporation miniSODAR ${ }^{\mathrm{TM}}$ (SOnic Detection and Ranging) can be found in accompanying manuals developed by Atmospheric Systems Corporation. A detailed description of the system and its components can be found in the manual entitled Description of the RDCDS Meteorological Component.

This manual was written for scientists or technicians who are tasked with the deployment and operation of the RDCDS network. The reader should have 1) experience working with laptop computers operating with the Windows XP operating system and 2) the technical background necessary to ensure that proper locations are selected for the individual meteorological instruments. 



\section{Contents}

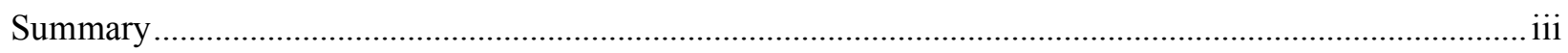

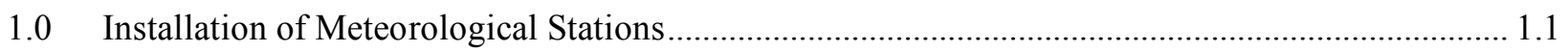

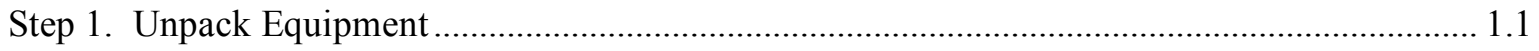

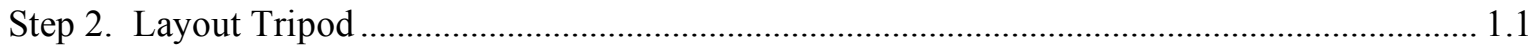

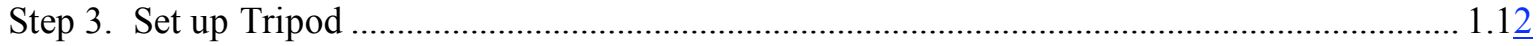

Step 4. Install Main Tripod Pipe ................................................................................................. 1.2

Step 5. Attach Anemometer ..........................................................Error! Bookmark not defined. $\underline{3}$

Step 6. Tilt Main Pipe Upward ................................................................................................. 1.3

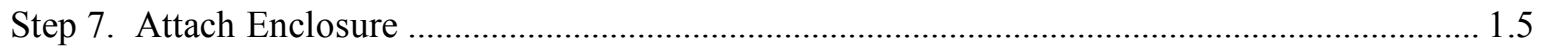

Step 8. Attach Antenna, Solar Panel, Radiation Shield, and Thermometer .................................... 1.6

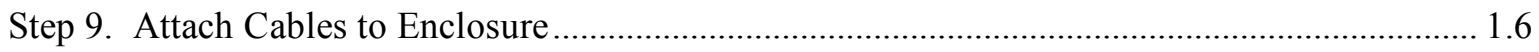

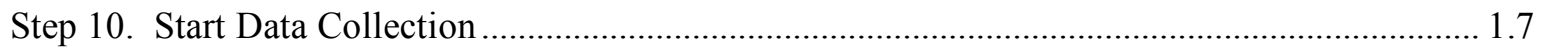

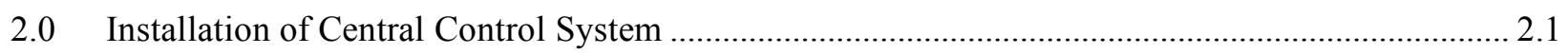

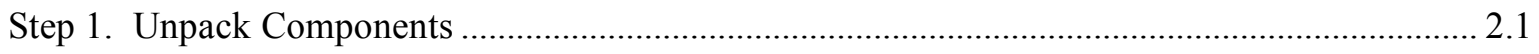

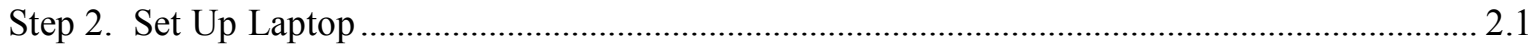

Step 3. Mount and Connect Antennae …................................................................................... 2.1

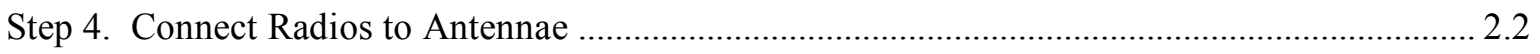

Step 5. Check the Station............................................................................................................. 2.2

Step 6. Check/Change Routing Path for Weather Stations ............................................................ 2.3

Step 7. Connect the Meteorological Central Control Computer to the Chemical Detector

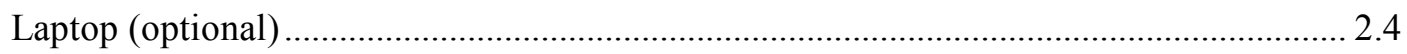

Step 8. Alter File with the Station Latitude and Longitude........................................................ 2.5

\section{Figures}

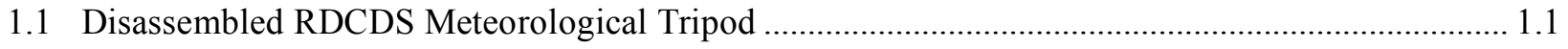

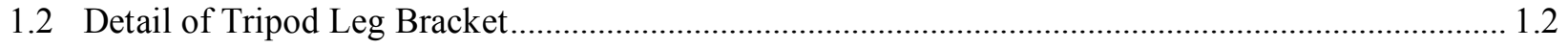

1.3 Main Pipe Attached to the Tripod with the Pin. Note the Shape of the Slot in the Tripod. ............... 1.3

1.4 Detail of Locking Clip on the Tripod with the Main Pipe Lifted into Place ...................................... 1.4

1.5 Enclosure Attached to the Main Pipe and Detail of the Sliding Clip at the Bottom of the

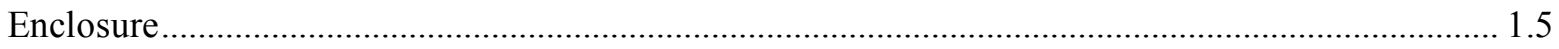

1.6 Nearly Completed Station with Radiation Shield, Solar Panel, and Radio Antenna ........................ 1.6

1.7 Sensor Enclosure with the Charging Regulator Marked by a Small Circle....................................... 1.7

2.1. Screen Shot of the Central Computer Screen with LoggerNet and SodarPro Running ..................... 2.3

2.2 Setup Screen Access from the LoggerNet Tool Bar ........................................................................ 2.4 



\subsection{Installation of Meteorological Stations}

This section describes the installation of a Rapidly Deployable Chemical Defense System (RDCDS) meteorological station. The tools needed for the installation are small and large Phillips screwdrivers, a one-half-inch socket, a one-half-inch box or combination wrench, and a crescent wrench.

\section{Step 1. Unpack Equipment}

The station consists of an anemometer, a thermometer, a radiation shield, an antenna, a solar panel, a data logger enclosure, a tripod, a battery, and associated cables. The temperature sensor (thermistor) and an external battery cable may be packed in the enclosure.

\section{Step 2. Layout Tripod}

The two basic parts of the tripod are legs and the main pipe (Figure 1.1). The main pipe has an extension section stored inside of it.

Figure 1.1. Disassembled RDCDS Meteorological Tripod 


\section{Step 3. Set Up Tripod}

Unfold the tripod legs. They should snap into place with a small pin that engages a hole in the back of the leg (Figures 1.2). A small lever located on the bottom of the bracket will release the leg.

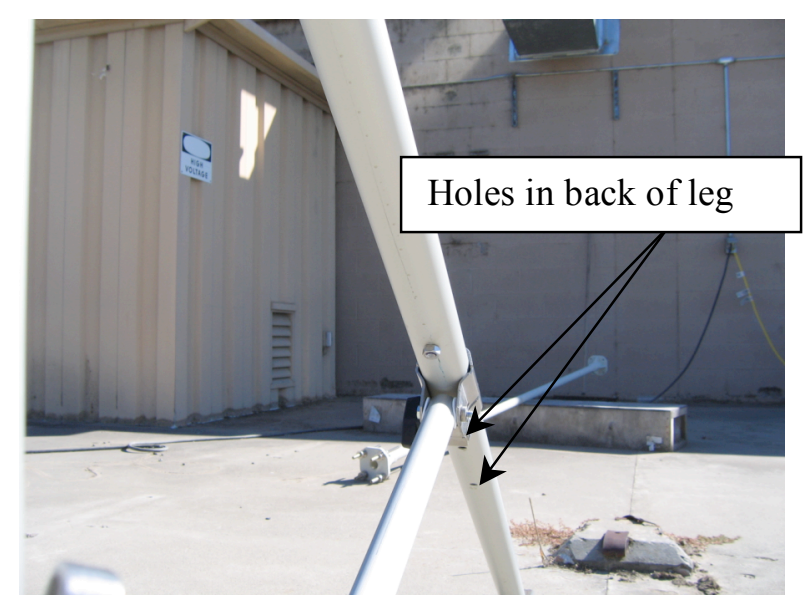

Figure 1.2. Detail of Tripod Leg Bracket

\section{Step 4. Install Main Tripod Pipe}

Align the pipe with the top angled slot in the tripod (Figure 1.3). Slide the pin attached to the tripod base through the highest slot and the main pipe. Use the highest slot. With the main pipe tilted downward, the pin should be located at the front of the slot. This orientation will allow for clearance when the main pipe is lifted.

Pull out the inside extension of the pipe to the desired wind sensor height, and fix the extension at that height using the bolt provided. Although three holes are located in the extension, the top hole should be used so that the anemometer can be mounted as high as possible. 

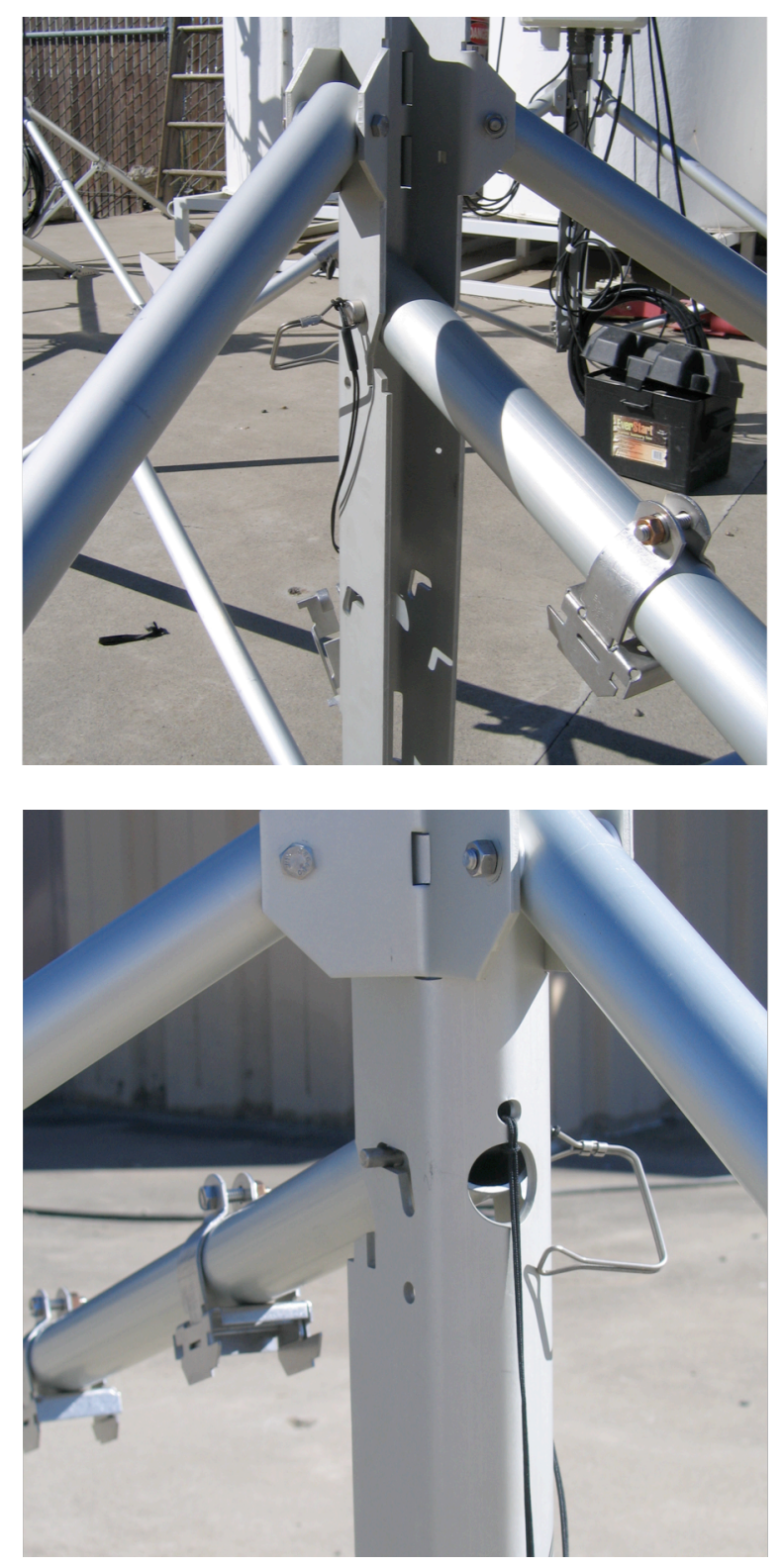

Figure 1.3. Main Pipe Attached to the Tripod (front and back) with the Pin. Note the Shape of the Slot in the Tripod.

\section{Step 5. Attach Anemometer}

At this point in the assembly process, the small anemometer-mounting pipe and the anemometer can be attached to the top of the extension, thus eliminating the need for a ladder. Note that the black rectangular box at the base of the wind sensor should be oriented due south.

\section{Step 6. Tilt Main Pipe Upward}

The pin holding the main pipe to the tripod should slide back and down. Attach the locking clip to the tripod to hold the pipe in place (Figure 1.4). 


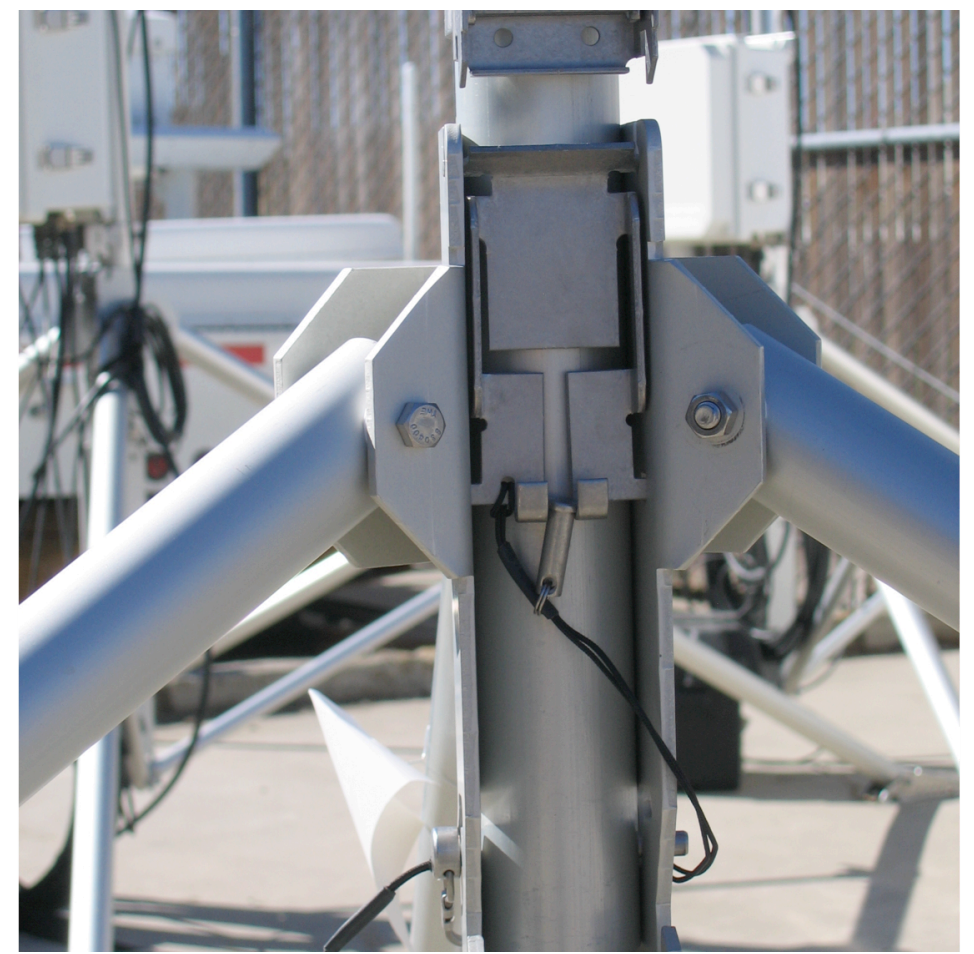

Figure 1.4. Detail of Locking Clip on the Tripod with the Main Pipe Lifted into Place 


\section{Step 7. Attach Enclosure}

Attach the sensor enclosure to the tripod using the clips attached to the tripod. Hang the enclosure over the top hook and then slide the lock on the bottom to the side to secure the enclosure in place (Figure $1.5)$.
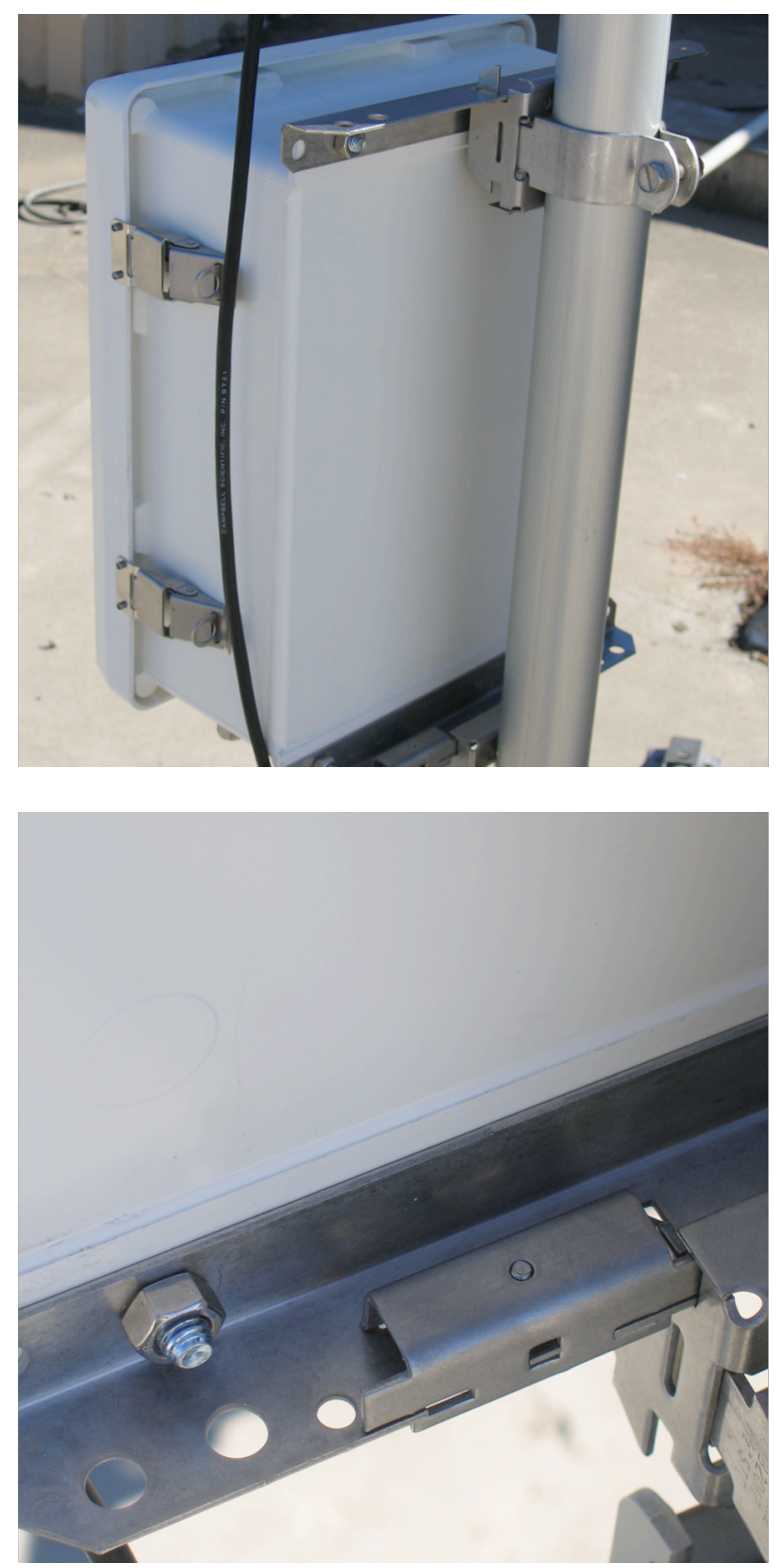

Figure 1.5. Enclosure Attached to the Main Pipe (top) and Detail of the Sliding Clip at the Bottom of the Enclosure (bottom) 


\section{Step 8. Attach Antenna, Solar Panel, Radiation Shield, and Thermometer}

Attach the solar panel, radio antenna, radiation shield, and thermometer to the main pipe (Figure 1.6). The thermocouple is mounted inside the radiation shield and is held in place by a small clamp at the bottom of the shield. With some deployments, it may be necessary to mount the antenna apart from the meteorological station to provide better performance of the network. The solar panel should face south and be tilted skyward for better performance.

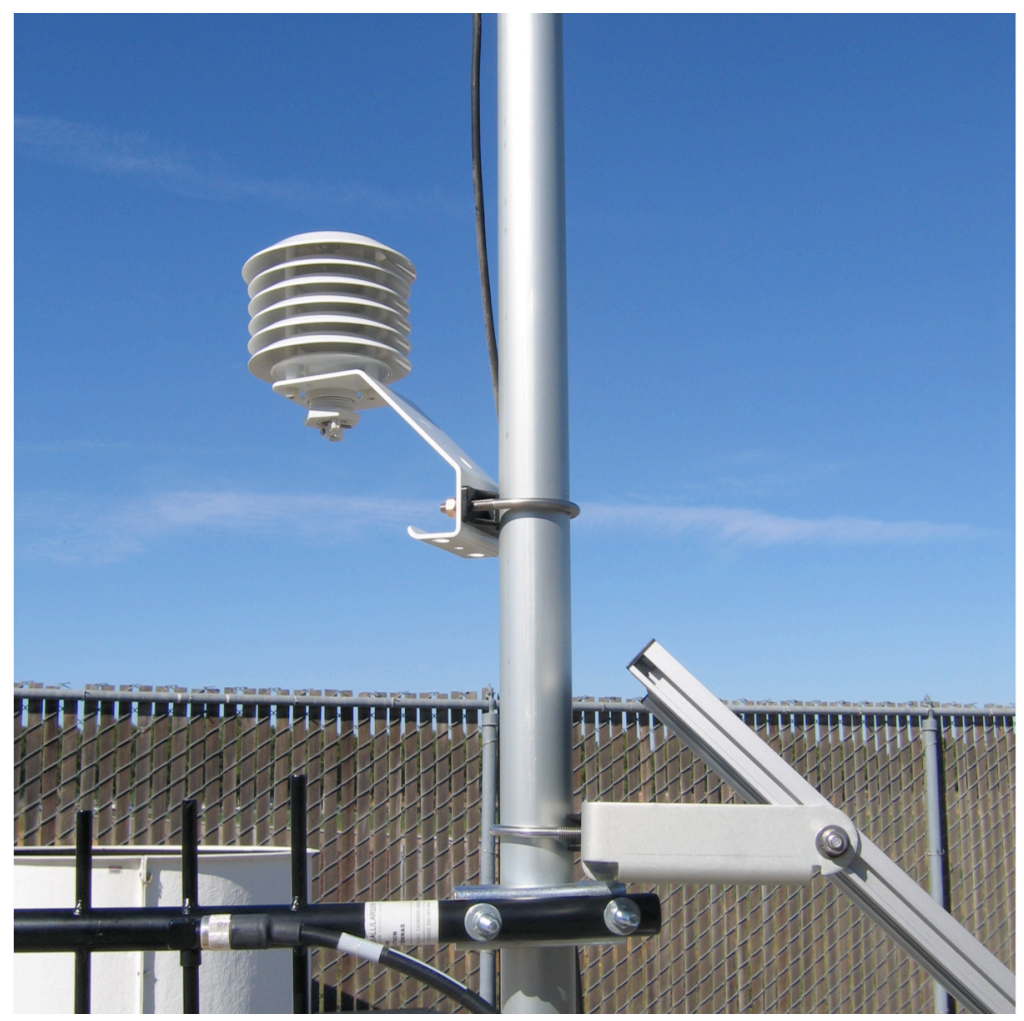

Figure 1.6. Nearly Completed Station with Radiation Shield, Solar Panel, and Radio Antenna. Note that the thermometer has not yet been mounted in the radiation shield.

\section{Step 9. Attach Cables to Enclosure}

Attach the cables from the anemometer, thermometer, solar panel, battery, and radio antenna to the enclosure. 


\section{Step 10. Start Data Collection}

Each station has the option of using either a small battery located within the enclosure, and/or a deep cycle (marine or automobile) battery located at the foot of the tripod. To begin operation of the station, the charging regulator must be switched on. The switch is circled in white in Figure 1.7. The internal battery (not shown) occupies the large cavity below the regulator and the data logger.

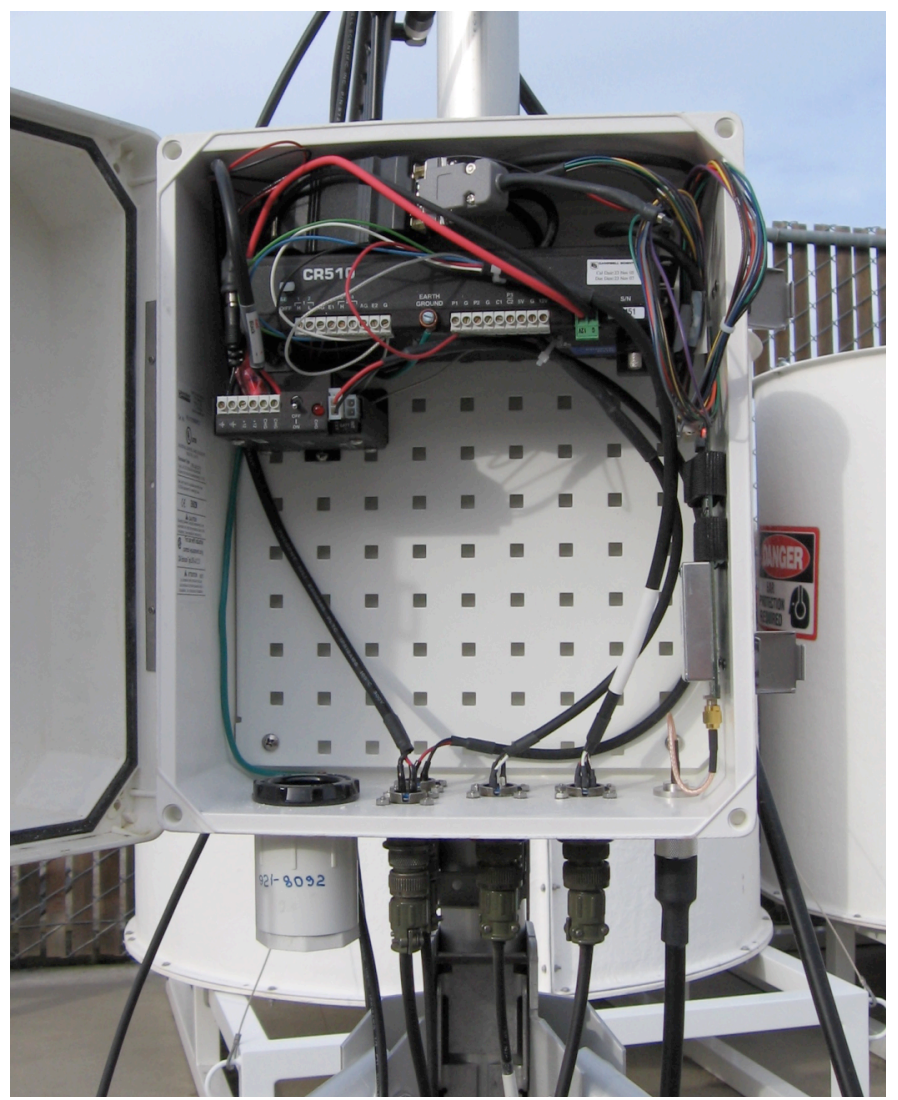

Figure 1.7. Sensor Enclosure with the Charging Regulator Marked by a Small Circle 



\subsection{Installation of Central Control System}

This section provides step-by-step instructions for the deployment of the RDCDS central control system. The tools needed are a small flat screwdriver and a Phillips screwdriver.

\section{Step 1. Unpack Components}

The central control system consists of the following components:

- laptop computer,

- two radios (with power supplies)

- omni-directional antenna

- one directional antenna (for use with miniSODAR)

- two antenna cables

- USB-to-serial adaptor

- two serial cables and one USB cable.

The spare-parts and accessories kit consists of the following:

- laptop computer

- radio (with power supply, backup for surface weather stations)

- omni-directional antenna

- GPS receiver

- miscellaneous cables

- tool box.

\section{Step 2. Set Up Laptop}

Set up the laptop computer. Using the USB cable, connect the USB-to-serial adapter (Keyspan USA94LWC) to one of the USB ports on the back of the laptop. Next, determine if the adapter has been recognized by the laptop and if its serial ports are mapped to COM4 through COM7.

Connect the meteorological network master radio (FGR-115RC in gray aluminum enclosure) to Port \#1 on the USB-to-serial adapter using standard serial cable (DB9 male to DB female). Connect the sodar master radio (black plastic enclosure) to Port \#2 on the USB-to-serial adapter using another standard serial cable.

\section{Step 3. Mount and Connect Antennae}

At present, no specialized mounting stands or tripods have been designed for antennae installation; instead, use appropriate local objects (fence, pole, etc.). 
Mount the omni-directional antenna (FG-9026) in a vertical orientation, preferably in a direct line-ofsight with the meteorological network, and at as high an elevation as possible. Connect the antenna to the meteorological master radio using the radio frequency $(\mathrm{RF})$ antenna cable.

Mount the Yagi antenna (YA5900W) with the cross bars oriented in the vertical plane, and point the antenna toward the miniSODAR. Connect the antenna to the sodar master radio using the RF antenna cable.

Note that these two antenna types are interchangeable, if necessary. For example, if the meteorological network master radio connects to the network via a repeater, then the directional antenna placed at the central station end and the omni-directional antenna placed at the repeater would be a better configuration.

\section{Step 4. Connect Radios to Antennae}

The radio in the gray aluminum enclosure is dedicated to the surface weather stations, and the radio in the black plastic enclosure is dedicated to the sodar. The radio for the surface weather stations should be connected to the omni-directional antenna, and the radio for the miniSODAR should be connected to the directional antenna.

Connect the radios to their power supplies. When the power is on, the meteorological master radio should display a blinking red TX light, and the CD light should glow a steady red. If the sodar is operational, the sodar master radio should display a steady green light and an intermittently flashing red light.

\section{Step 5. Check the Station}

Turn the laptop on. The LoggerNet and the SodarPro programs should start automatically (Figure 2.1). If an operating weather station is detected, data transfer should start, and the Real Time Monitor and Control Development Run-Time (RTMC RT) display should update. 


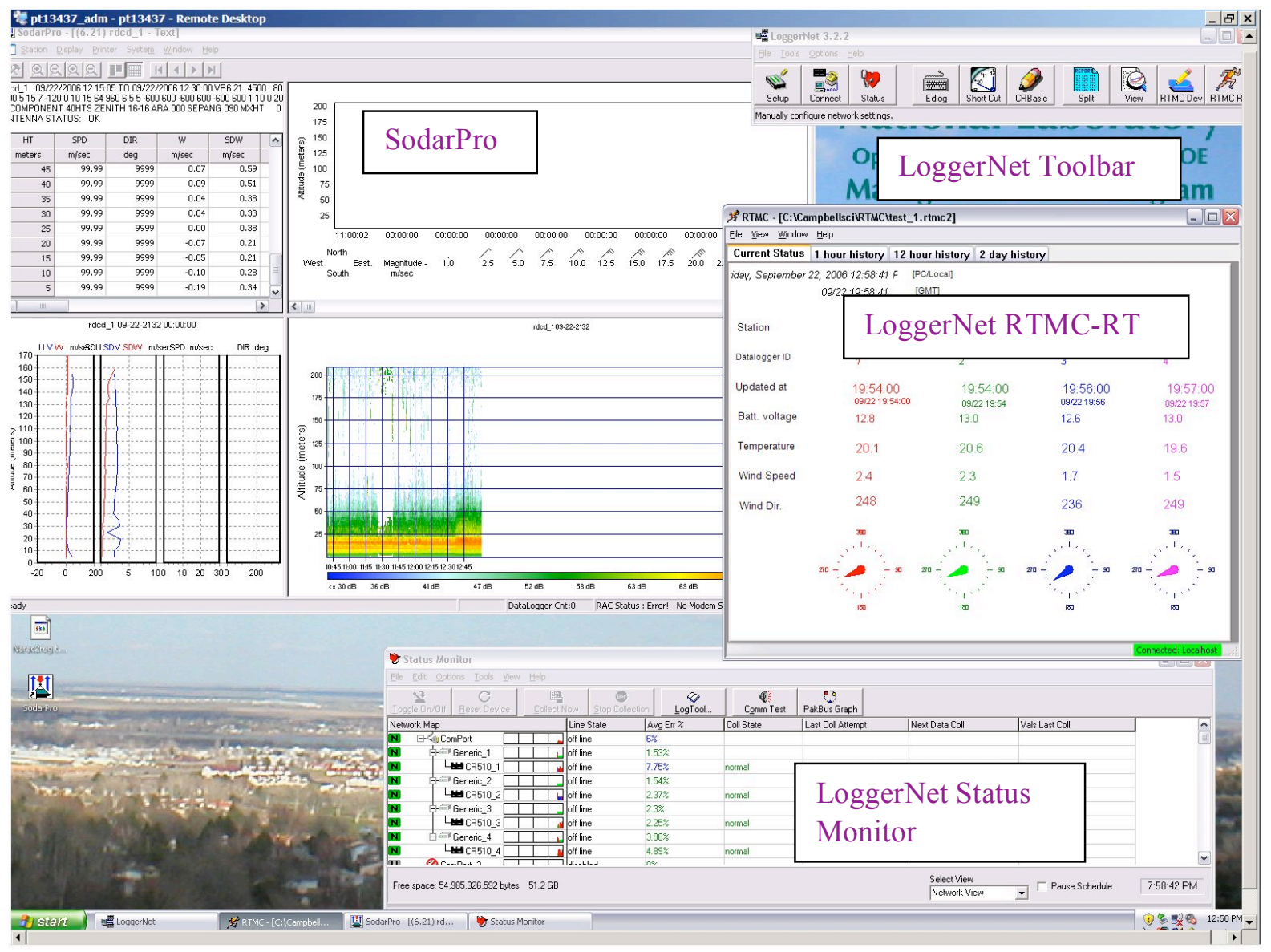

Figure 2.1. Screen Shot of the Central Computer Screen with LoggerNet (Tool Bar, Status Monitor, and RTCM-RT) and SodarPro Running. If one of the auxiliary utilities is not running (i.e., Status Monitor or RTCM-RT), it can be started from the Tool Bar.

\section{Step 6. Check/Change Routing Path for Weather Stations}

There may be deployments in which direct communication between a weather station and the central control system might be unreliable or impossible. In these cases, it will be necessary to use one of the weather stations (or the backup station) as a radio repeater to establish communications. The LoggerNet Setup utility is used to make this change.

Start the Setup from the LoggerNet Tool Bar; choose "Generic_X" device, where X is the same number as the station that the user would like to access via a repeater (station 2 in Figure 2.2); and choose the "Modem" property page. Note that the "Dial Script" line contains:

T"ATXC9ATD9218092" R"OK"1200

In the Dial Script, ATXC9 indicates which line in the Call Book of the master radio is to be used as a repeater path, and the $\mathbf{9 2 1 8 0 9 2}$ identifies a specific radio. By our convention, the Call Book of the master radio contains stations 1 through 4 in lines 1 through 4, and blanks in lines 8 and 9; therefore, the above Dial Script requests direct connection (no repeater). To change the Dial Script to a connection via a 
repeater, replace line 9 with the repeater station number (i.e., 1, 3, or 4 for the RDCDS network) in the ATXC part of the Dial Script, such that the script looks like (for the case where station 1 will be used as the repeater):

T"ATXC1ATD9218092" R"OK"1200

Next, click on the "Apply" button. Now you may exit the Setup utility. Note that this is a "permanent" change that will remain in effect until changed using the procedure described above.

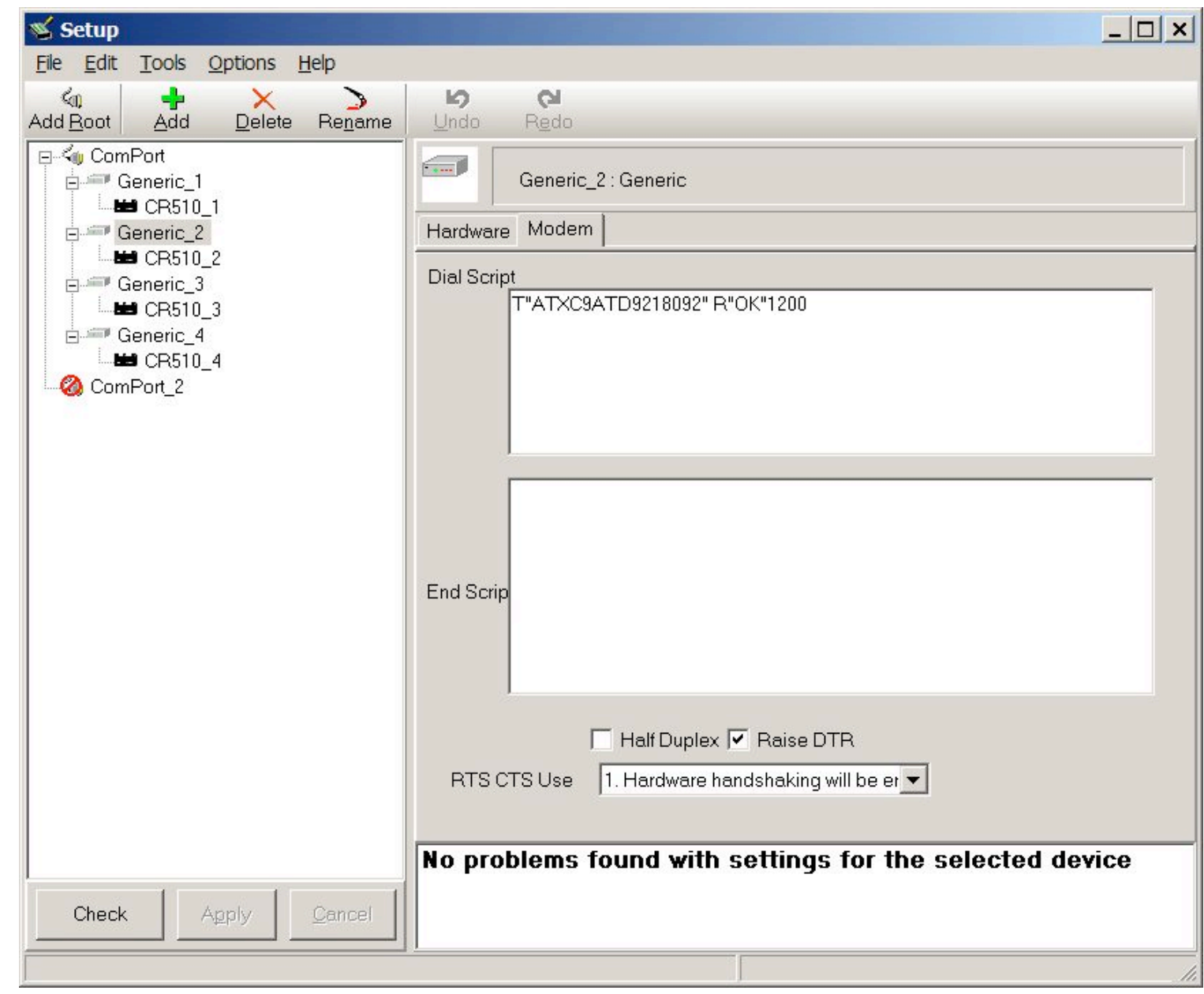

Figure 2.2. Setup Screen Access from the LoggerNet Tool Bar

\section{Step 7. Connect the Meteorological Central Control Computer to the Chemical Detector Laptop (optional)}

Connecting the meteorological central control computer to the chemical detector laptop is necessary only for a full deployment of the RDCDS system. The Internal Protocol (IP) address of the laptop may need to be changed. 


\section{Step 8. Alter File with the Station Latitude and Longitude}

A text file, stationDef.txt, contains the latitudinal and longitudinal positions of the weather stations.

This file can be found in C: CampbellscilLoggerNet. Each station is assigned an arbitrary number. The latitudes and longitudes of the stations can be obtained with the help of the GPS receiver. 